\title{
Current Modalities of Fibrosis Assessment in Non-alcoholic Fatty Liver Disease
}

\author{
Mark CC Cheah ${ }^{1}$, Arthur J McCullough ${ }^{2,3}$ and George Boon-Bee Goh*1,4 \\ ${ }^{1}$ Department of Gastroenterology \& Hepatology, Singapore General Hospital, Singapore; 2Department of Gastroenterology, \\ Cleveland Clinic, Ohio, USA; ${ }^{3}$ Department of Pathobiology, Cleveland Clinic, Ohio, USA; ${ }^{4}$ Duke-NUS Medical School, Singapore
}

\begin{abstract}
Non-alcoholic fatty liver disease (NAFLD) is a burgeoning global health concern. In the subset of NAFLD patients with non-alcoholic steatohepatitis (NASH), the presence of significant fibrosis at index assessment is associated with poor prognosis and increased mortality. Hence, there is a growing need to accurately assess and stage fibrosis. Liver biopsy, the current gold standard, has limitations with sampling error and is invasive, with associated inherent risk. This has led to a host of non-invasive means of assessing fibrosis, which has garnered relevance in a disease that requires serial assessment of fibrosis longitudinally over time. This review discusses, comprehensively, the various tools available to the clinician for the assessment of fibrosis, including the various scoring systems used in liver biopsy, the non-invasive means of serum biomarkers, such as the highly-validated NAFLD fibrosis score, and the imaging-based modalities, such as transient elastography and magnetic resonance elastography. Citation of this article: Cheah MCC, McCullough AJ, Goh GBB. Current modalities of fibrosis assessment in nonalcoholic fatty liver disease. J Clin Transl Hepatol 2017;5(3): 261-271. doi: 10.14218/JCTH.2017.00009.
\end{abstract}

\section{Introduction}

Non-alcoholic fatty liver disease (NAFLD) is the most common chronic liver disease worldwide, with a global prevalence estimated at $25 \%$ of the world's population, but with geographical variability; the highest prevalence has been noted amongst western countries. ${ }^{1,2}$ NAFLD is closely associated

\section{Keywords: NAFLD; Fibrosis assessment; Modalities.}

Abbreviations: 2-D, 2-dimensional; 3-D, 3-dimensional; ALT, alanine transaminase; APRI, AST platelet ratio index; ARFI, acoustic resonance force impulse; AST, aspartate transaminase; AUROC, area under the receiver operating characteristic curve; BAAT, BMI, age, ALT, triglycerides; BARD, BMI, AST/ALT ratio, DM; BMI, body mass index; CAP, controlled attenuation parameter; CRN, Clinical Research Network; DM, diabetes mellitus; ELF, enhanced liver fibrosis; FT, FibroTest ${ }^{\circledR}$; GGT, gamma-glutamyl transpeptidase; HA, hyaluronic acid; HCC, hepatocellular carcinoma; IFG, impaired fasting glucose; LSM, liver stiffness measurement; MRE, magnetic resonance elastography; MRI, magnetic resonance imaging; NAFLD, non-alcoholic fatty liver disease; NAS, NAFLD activity score; NASH, nonalcoholic steatohepatitis; NFS, NAFLD fibrosis score; P3NP, procollagen $3 \mathrm{~N}$-terminal peptide; SAF, steatosis, activity, fibrosis; SSI, supersonic shearwave imaging; TIMP-1, tissue inhibitor of metalloproteinase-1; VCTE, vibration controlled transient elastography.

Received: 12 February 2017; Revised: 13 April 2017; Accepted: 29 April 2017 *Correspondence to: Dr George Boon-Bee Goh, Department of Gastroenterology \& Hepatology, Singapore General Hospital, 20 College Road, Singapore 169856, Singapore. Tel: +65-62223322, Fax: +65-62273623, E-mail: goh. boon.bee@singhealth.com.sg with obesity, type 2 diabetes, dyslipidemia and other metabolic risk factors, and is commonly regarded as the hepatic component of metabolic syndrome. ${ }^{1,3-5}$ Studies have consistently demonstrated the increasing clinical burden of NAFLD, both as a function of increasing disease prevalence in parallel to the obesity and metabolic syndrome epidemic and also corroborated by continued emergence of natural history data. $3,6,7$

In the United States, NASH-related cirrhosis is the fastest growing indication for liver transplantation. Separately, another study demonstrated a 10 -fold increase in $\mathrm{NASH}-$ associated hepatocellular carcinoma (HCC) from 2000 to 2010 , accounting for $34.8 \%$ of all HCC cases. ${ }^{8}$ In addition, relative to the general population, patients with NAFLD have been reported to have increased mortality, with the top three causes of death attributed to cardiovascular-, malignancy- and liver-related causes. ${ }^{9-12}$ From the public health perspective, the direct medical cost of caring for a patient with NAFLD has been estimated to be about $\$ 1,613$ or $€ 1,163$ per patient annually in the United States and Europe respectively, representing a substantial economic burden. ${ }^{6}$ This sets a worrying precedent for the future landscape of liver disease.

NAFLD is defined by the presence of excessive hepatic steatosis ( $5 \%$ or more) in the absence of other liver disease etiologies. ${ }^{13-15}$ It is a heterogeneous disease, manifesting a spectrum of phenotypes, ranging from simple steatosis, which is traditionally considered relatively benign, to the more aggressive non-alcoholic steatohepatitis (NASH), seen in 10 to $25 \%$ of the cases. Up to one-third of the patients with $\mathrm{NASH}$ may progress onwards to liver cirrhosis and other liverrelated complications, such as HCC. In particular, significant fibrosis at the time of diagnosis is the most important histological feature associated with mortality in NASH, regardless of the presence or severity of other histologic features. ${ }^{16-18}$ In addition, with the advent of potential emergence of potent anti-fibrotic agents for the treatment of NASH, the accurate assessment of liver fibrosis becomes even more pertinent, not only for identifying suitable patients for treatment, but also in the evaluation of treatment efficacy.

In this review, we explore the different modalities of fibrosis assessment in NAFLD, ranging from histology and non-invasive biomarkers to predictive scores and imaging measures.

\section{Liver histology}

The liver biopsy, albeit imperfect, remains the gold standard for the diagnosis, assessment of disease activity and response to 
treatment in NAFLD. In an early landmark study, Skelly et al. ${ }^{19}$ highlighted the importance of liver biopsy in the context of NAFLD; in their cohort of 354 patients who underwent liver biopsy for otherwise unexplained abnormal liver tests, $66 \%$ had fatty liver, $50 \%$ of which had NASH, while a further $19 \%$ had other treatable causes, such as autoimmune hepatitis, hemochromatosis and primary biliary cirrhosis.

An adequate histology specimen would depend on obtaining a sufficient core of at least $2 \mathrm{~cm}$ long, comprising 10 or more portal tracts. ${ }^{15-20}$ Specimens should be processed with hematoxylin and eosin stain and specifically with Masson's Trichrome stain to assess fibrosis. Other stains may also be used as deemed necessary by the pathologist in the interrogation of the specimen. Finally, the review of specimens should be carried out by at least two pathologists.

Fibrosis in NAFLD evolves in a distinctive pattern, usually beginning in the pericentral zone 3 region. This fibrosis can increase in density and complexity, eventually progressing to bridging fibrosis and cirrhosis. ${ }^{21}$ There are three established scoring assessment systems currently in regular use for NAFLD: the Brunt system, NASH Clinical Research Network (CRN) system and the Steatosis, Activity, Fibrosis (SAF) system, all of which incorporate the assessment of fibrosis. ${ }^{14,22,23}$ According to the Brunt system, the severity of fibrosis is defined by four stages, with stage 1 representing zone 3 perisinusoidal fibrosis, stage 2 including portal fibrosis with the zone 3 perisinusoidal fibrosis, stage 3 representing bridging fibrosis and stage 4 representing cirrhosis. ${ }^{22}$ The Brunt system was subsequently modified in the NASH CRN system, which differed from the Brunt staging by further subdividing stage 1 fibrosis into three sub-stages, whereby stage 1 a and $1 \mathrm{~b}$ represents zone 3 perisinusoidal fibrosis, differentiated by the character of collagen deposition (delicate or dense), while stage $1 \mathrm{c}$ represents portal or periportal fibrosis, which is more commonly seen in pediatric patients. ${ }^{14}$ The SAF system is the most recently proposed scoring system, developed from a study of 679 obese patients undergoing liver biopsy prior to bariatric surgery. Fibrosis stage $(F)$ was assessed as Stage 0 (F0) no activity, stage 1 (F1) $1 \mathrm{a}$ or $1 \mathrm{~b}$ as perisinusoidal zone 3 of $1 \mathrm{c}$ portal fibrosis, stage 2 (F2) as perisinusoidal and periportal fibrosis without bridging, stage $3(F 3)$ as bridging fibrosis and stage 4 (F4) as cirrhosis. The SAF system differs from the NASH CRN system in that it incorporates fibrosis score into the final SAF score, while for the NASH CRN system, fibrosis stage is reported separately from the NALFD activity score (known as NAS). Besides fibrosis, the liver biopsy reveals a treasure trove of other information integral to the assessment of NAFLD, including grading of steatosis, inflammatory activity and damage, which can be perused in the many excellent reviews on this subject. ${ }^{21,24,25}$

\section{Limitations of liver biopsy}

Liver biopsies, however, are not without issue. Firstly, inherent to its invasive nature are the procedural risks of bleeding, visceral injury and even death. ${ }^{26}$ Secondly, the biopsy assesses only a small fraction $\left(1 / 50,000^{\text {th }}\right)$ of the entire liver parenchyma. Whilst steatosis itself is diffuse, the distribution and degree of steatohepatitis/fibrosis within the liver can be heterogeneous; hence, inaccurate sampling and staging may result. ${ }^{27-30}$ Thirdly, considering the semiquantitative nature of histologic assessment, there remains the potential for intra- and inter-observer variability. ${ }^{31,32}$ Furthermore, bearing in mind the huge number of patients with NAFLD and NASH potentially, liver biopsy cannot be applied as a screening tool or for first-line investigation in the approach to NAFLD.

Hence, there is a growing impetus advocating for noninvasive means of assessing fibrosis that are reliable, reproducible, easy to perform and inexpensive. The optimal test should not only allow for effective grading and staging, but also allow for the monitoring of disease progression and response to treatment.

\section{Serum biomarkers/composite scores}

Patients with NAFLD or NASH are largely asymptomatic at presentation. At index evaluation, routine laboratory tests, such as a serum panel of liver enzymes (albumin, bilirubin, alanine aminotransaminase (ALT), aspartate aminotransaminase (AST), gamma-glutamyl transpeptidase (GGT)), full blood count and prothrombin time/international normalized ratio may be performed. Elevated ALT and AST levels are the predominant finding in patients with NAFLD, with levels typically not more than 5 times the upper limit of normal. Individually, the liver enzymes do not correlate very well with severity of NAFLD. Indeed, in one study, normal levels of ALT and AST were seen in more than two-thirds of patients with $\mathrm{NASH}$, with the entire range of histological findings of NAFLD, including active necroinflammation, fibrosis and cirrhosis found in patients with normal ALT values. ${ }^{33}$ A separate study reported that there was no difference in the rate of advanced fibrosis between patients with normal or elevated ALT and there was no optimal ALT level to predict advanced fibrosis. ${ }^{34}$ Rather it may be the pattern of AST to ALT ratio that may provide clues on the stage of fibrosis, and this concept is incorporated into several of the composite risk scores for advanced fibrosis.

\section{NAFLD fibrosis score (NFS)}

The NFS is arguably the most studied scoring system and is recommended by the American Association for the Study of Liver Diseases $(2012)^{35}$ and European Association for the Study of the Liver (2015) $)^{36}$ in the assessment of patients for advanced fibrosis. In comparison to other composite scores for advanced fibrosis, the NFS was found to perform favorably. ${ }^{37}$ The NFS was developed in a multicenter study of 733 patients with biopsy-proven NAFLD. ${ }^{38}$ Four-hundredand-eighty patients were used to develop the scoring system, with the remaining two-hundred-and-fifty-three patients used for validation. Six variables including age, hyperglycemia, body mass index (BMI), platelet count, albumin and the AST/ALT ratio were identified to be independent indicators of advanced fibrosis. Using these variables, a regression formula was applied to create the NFS score. Two optimal cut-offs were identified, one to exclude advanced fibrosis $(<-1.455)$ and the other to indicate the presence of advanced fibrosis $(>0.676)$. Using these cutoffs, the NFS score was able to discriminate patients with advanced fibrosis (stage $\geq 3$ ) from patients without (stage $0-2$ ), with an area under the receiver operating characteristic curve (AUROC) of 0.82 (95\% CI $0.76-0.88)$ in the validation cohort.

The NFS score was validated in another study comparing various non-invasive measures of advanced fibrosis, with an AUROC of 0.81 (95\% CI, 0.71-0.91), performing well when compared with the FIB-4, BARD score, and AST/ALT ratio. ${ }^{37}$ 
In a meta-analysis of 13 studies consisting of 3,064 patients, ${ }^{12}$ the NFS had an AUROC of 0.85 for predicting advanced fibrosis $(F \geq 3)$. A score of $<-1.455$ had $90 \%$ sensitivity and $60 \%$ specificity for excluding advanced fibrosis, whereas a score of $>0.67$ had $67 \%$ sensitivity and $97 \%$ specificity for identifying the presence of advanced fibrosis. While the NFS represents an easily accessible tool, incorporating routine clinical parameters, and has good diagnostic performance, a considerable proportion of patients (between $20-58 \%$ ) do fall into the indeterminate "grey zone". ${ }^{12}$

Nevertheless, and perhaps most importantly, the NFS has been shown to have prognostic value for hepatic complications and mortality in patients with NAFLD. ${ }^{39}$ In a cohort study of 302 patients with 20 years of follow-up, ${ }^{40}$ the NFS cut-off of $>0.67$ was used to identify patients with a high probability of advanced fibrosis. During the follow-up, all-cause death occurred in $46.2 \%$, with the composite endpoint of all-cause mortality, cardiac and/or liver complications occurring in $61.5 \%$ of patients in this group. The NFS has also been validated in an Asian (Chinese) cohort; ${ }^{41}$ a similar high negative predictive value of $91 \%$ was corroborated in this study, when the low cut-off of $<-1.455$ was applied. However, only two patients in that study exceeded the high cut-off of 0.676 , limiting the ability of this study to validate the high cut-off. This underscores the potential differences in an Asian cohort where the development of visceral obesity and metabolic complications may occur at a lower BMI.

\section{FibroTest $^{\circledR}$ (FT)/Fibrosure ${ }^{\circledR}$}

FibroTest $^{\circledR}$ (FT) or Fibrosure represent the same test, marketed commercially under different names in the United States and Europe, respectively. It is a panel comprising total bilirubin, GGT, $\alpha 2$-macroglobulin, haptoglobin and apolipoprotein A1 corrected for age and sex. Besides the previous validation as a marker for advanced fibrosis in hepatitis $B$ and $C$ populations, ${ }^{37,42}$ it has also been evaluated in the context of NAFLD. ${ }^{43}$ Ratziu et $a l .{ }^{43}$ evaluated the utility of FT in two cohort groups with biopsy-proven NAFLD (group 1, $n=170$, from a single reference center) and (group $2, n=97$, from a multicenter cohort) compared with 954 blood donors as controls. The study demonstrated that FT had an AUROC of 0.86 and 0.92 for predicting F2-4 fibrosis and F3-4 fibrosis, respectively. A lower FT cut-off of 0.30 had a $90 \%$ negative predictive value for advanced fibrosis (sensitivity of $77 \%$ ) while a higher FT cut-off of 0.70 had a $73 \%$ positive predictive value for advanced fibrosis (specificity of $98 \%$ ). ${ }^{43}$ The caveat would be that this test may not be easily accessible, as several of the variables required ( $\alpha 2$-macroglobulin, haptoglobin and apolipoprotein A1) are not readily measureable in most routine clinical laboratories.

\section{AST to platelet ratio (APRI)}

The APRI score is a simple index that was initially developed and validated by Wai et al. ${ }^{44}$ in the chronic hepatitis $C$ virusinfected population for identifying patients with advanced fibrosis ( $\geq F 3$ ). In a retrospective cohort study of 358 patients with biopsy-proven NAFLD, an APRI score of $>1$ had a likelihood ratio for significant fibrosis of 4.2 , with sensitivity and specificity of $30 \%$ and $92.8 \%$ respectively. ${ }^{46}$ Other studies that compared various composite predictive scores suggested that APRI performed less favorably in detecting advanced fibrosis, with AUROCs ranging from 0.67 to $0.78 .^{37,46,47}$ As such, there is less enthusiasm for the use of APRI in the context of NAFLD.

\section{AST/ALT ratio}

The AST/ALT ratio has been shown to be reasonably accurate in detecting cirrhosis in patients with chronic hepatitis C. ${ }^{48}$ Data validating the use of the AST/ALT ratio as a standalone scoring system in NASH is scarce. In one NASH cohort, the AST/ALT ratio was shown to be an independent predictor for advanced fibrosis $(F \geq 3)$ /cirrhosis in the multivariate analysis. ${ }^{49}$ Separately, McPherson et $a^{50}$ reported on the positive performance of AST to ALT ratio to detect advanced fibrosis in a cohort of 145 patients with biopsyproven NAFLD, with an AUROC of 0.83 , sensitivity of $74 \%$ and specificity of $78 \%$. With a high negative predictive value of $93 \%$ and a modest positive predictive value of $44 \%$, the AST to ALT ratio can be useful in ruling out advanced fibrosis as an initial screening tool. ${ }^{50}$ One caveat is the interpretation of AST/ALT ratio with age; with advancing age, ALT levels progressively decline, while AST levels remain stable. This can result in increasing AST/ALT ratios in both patients with and without advanced fibrosis. Hence, cautious interpretation of ALT and AST/ALT ratio is warranted in the context of advancing age. ${ }^{51}$ Nonetheless, the importance of the AST/ALT ratio to detect advanced fibrosis is often acknowledged and even incorporated in various other more complex scoring systems, such as the NFS and BARD.

\section{FIB-4}

The FIB-4 was originally developed for use in assessing fibrosis in the hepatitis $C$ virus/human immunodeficiency virus co-infected population. ${ }^{52}$ The score comprises readily available clinical data of: age, AST, ALT and platelet counts. Shah et $a l .{ }^{47}$ validated the FIB-4 for use in NAFLD, in their comparative study against other non-invasive scoring systems (FT, Fibroscan, BARD, NFS and NASH score), using a cohort of 541 patients from the NASH CRN network. In their study, the AUROC for FIB-4 for identifying patients with advanced fibrosis (F3-F4) was 0.802 (95\% CI: 0.758-0847), which was comparable to the NFS but higher than the other scoring systems it was compared against. A FIB-4 score of $\geq 2.67$, had an $80 \%$ positive predictive value and a FIB- 4 score of $\leq 1.30$ had a $90 \%$ negative predictive value for advanced fibrosis. These results were corroborated in other similar studies comparing the performance of non-invasive markers of advanced fibrosis in NASH. ${ }^{37,46,53,54}$ Interestingly, FIB-4 has also shown good performance in the prediction of mild to moderate fibrosis in NAFLD. Comparing several noninvasive models for predicting hepatic fibrosis, a FIB-4 cut-off of 1.43 had the best AUROC $(0.821 ; 95 \% \mathrm{CI}: 0.75-0.891)$ to detect stage 1 fibrosis or higher. ${ }^{55}$

\section{BAAT score}

The BAAT Score was one of the early predictive scores developed to assess risk of fibrosis in overweight patients with NAFLD. It is a composite score utilizing four variables (BMI, Age, ALT and Triglycerides) that were found to independently correlate with septal fibrosis on liver biopsy, based on multivariate analysis of a retrospective cohort of 93 patients; that finding was further validated in a prospective cohort of 66 patients. ${ }^{56}$ The BAAT score is the weighted 
sum of BMI ( $\geq 28=1,<28=0$ ), age at liver biopsy ( $\geq 50$ years $=1 ;<50=0), \operatorname{ALT}(\geq 2 \mathrm{~N}=1, \leq 2 \mathrm{~N}=0)$ and serum triglycerides $(\geq 1.7 \mathrm{mmol} / \mathrm{L}=1,<1.7=0)$, with a score ranging from 0 to 4 . A score of 0 had $100 \%$ negative predictive value for diagnosis of septal fibrosis, with a BAAT score cut-off of 2.86 having an AUROC of 0.84 for identifying patients with septal fibrosis. Data on the utility of BAAT score remains scarce. In a more recent study comparing various scores to predict fibrosis, the performance of BAAT demonstrated an AUROC of 0.676 (95\% CI: 0.577-0.774) and 0.615 ( $95 \% \mathrm{CI}: 0.520-0.710)$ to detect stage 1 fibrosis or more and advanced fibrosis respectively. ${ }^{55}$

\section{BARD score}

The BARD score developed by Harrison et al. ${ }^{57}$ was generated from logistic regression analysis of a retrospective cohort of 827 patients with NAFLD. Three variables were identified and used in a weighted sum score: $\mathrm{B}$ : $\mathrm{BMI} \geq 28=1$ point, $A$ AR: AST/ALT ratio $\geq 0.8=2, D M=1$ point. In the validation study, a score of 2-4 had an AUROC of 0.81 (for patients with advanced fibrosis ( $\geq F 3$ ) vs patients with simple steatosis or F0-F2 fibrosis). The BARD score was associated with an odds ratio of 17 (95\% CI: 9.2 to 31.9) for advanced fibrosis (F3-F4), with a negative predictive value of $96 \%$ for ruling out advanced fibrosis if the score as $0-1$. In other studies, the BARD consistently reported a high negative predictive value, ranging 81 to $97 \% .{ }^{58-60}$ However, in the study by Ruffilo et al., ${ }^{59}$ the BARD score only had a sensitivity of $51.4 \%$ and specificity of $77.2 \%$ for advanced fibrosis. The variable performance of the BARD score may be contributed to some extent by the overestimation of BMI and presence of diabetes. ${ }^{61}$

\section{Enhanced liver fibrosis (ELF) test}

The ELF test is a simplified algorithm of the Original European Liver Fibrosis test ${ }^{62,63}$ and has been validated in a variety of chronic liver diseases. It comprises a panel of amino-terminal propeptide of type III procollagen (PIIINP), tissue inhibitor of metalloproteinase 1 (TIMP-1) and hyaluronic acid. In the initial validation cohort of 196 patients, the ELF performed well, with an AUROC of 0.90 (95\% CI: 0.84-0.96) for distinguishing advanced fibrosis ( $\geq F 3$ ). A threshold of 0.3576 had a sensitivity of $80 \%$, specificity of $90 \%$, positive predictive value of $71 \%$ and negative predictive value of $94 \%$ for severe fibrosis. Similar results have also been shown for the pediatric population. ${ }^{64}$ Furthermore, some data suggest that the ELF test to be a good predictor of liver-related morbidity and mortality in chronic liver disease, including NAFLD. ${ }^{65}$

Recently, the ELF score has been endorsed by the National Institute of Clinical Excellence (United Kingdom) in their guidelines for management of NAFLD, citing the high accuracy of ELF for identifying patients with advanced fibrosis. Further, the ELF score proved most cost-effective in their analysis when compared to other serum based scoring systems or imaging modalities such as vibration controlled transient elastography (VCTE) or magnetic resonance elastography (MRE). ${ }^{66}$ In adults, the guidelines recommend screening for advanced fibrosis using ELF every 3 years. As with the FT, the ELF test may have limitations in usage as it is based on markers not routinely available.

\section{FibroMeter for NAFLD}

FibroMeters are panels of serum markers and clinical parameters that were developed to evaluate hepatic fibrosis depending on the underlying etiology. FibroMeters for viral hepatitis, ${ }^{67}$ alcoholic $^{67}$ and NAFLD have been developed. The FibroMeter for NAFLD comprises age, body weight, glycemia, platelets, AST, ALT and ferritin. In a comparative study ${ }^{68}$ of FibroMeter for NAFLD against the NFS and APRI, the FibroMeter for NAFLD had the highest AUROC for significant fibrosis ( $\geq F 2$ ) of 0.943 (95\% CI: $0.91-0.98$ ) compared to the NFS 0.885 (95\% CI: $0.83-0.93$ ) versus the APRI 0.866 (95\% CI: $0.81-0.92$ ). The FibroMeter for NAFLD also demonstrated excellent accuracy when three intervals of fibrosis were applied: F0/F1 (95\% accuracy), F0/F1/F2 (75\% accuracy), F2/F3/F4 (87.9\% accuracy) with an overall accuracy of $91.9 \%$. Overall, the diagnostic performance of Fibrometer for NAFLD was better for intermediate fibrosis stages $(\mathrm{F} 1 / 2)$ and less robust for advanced fibrosis (F3/4).

\section{Summary of serum biomarkers/composite scores}

Amongst the array of composite scores available to the clinician, the NFS and FIB-4 standout in having a high AUROC for advanced fibrosis, as compared to the other scoring systems, ${ }^{37,46,47,53-55}$ and have the advantage of using readily available clinical and biochemical parameters. Importantly, the NFS has been shown to have prognostic value for hepatic decompensation and mortality. ${ }^{39}$ Other composite scores, such as the ELF and Fibrometer, show promise with their excellent AUROC for advanced fibrosis; ${ }^{62,63}$ Fibrometer, in particular, showed better performance than NFS in one comparative study. ${ }^{68}$ However, the proprietary nature, and potential costs of these newer tests have perhaps limited the enthusiasm and accessibility for their mainstream use. A summary of the serum biomarker/composite scores are available in Table 1.

\section{Elastography as a surrogate for Fibrosis assessment}

\section{VCTE by Fibroscan ${ }^{\circledR}$}

VCTE by Fibroscan ${ }^{\circledR}$ measures shear wave velocity of a low frequency shear wave $(50 \mathrm{~Hz})$ transmitted via an ultrasound probe in the liver as an estimate of liver stiffness. Conceptually, with increased liver stiffness, shear wave velocity correspondingly increases. Besides the non-invasive nature of evaluation, VCTE is advantageous in having excellent interand intra-operator reproducibility and is arguably able to assess a larger area of liver parenchyma (approximately $1 \mathrm{~cm} \times 4 \mathrm{~cm}$ ), the volume of which is about 100 times that of a liver biopsy, which samples only $1 / 50,000$ of the liver volume. $^{69,70}$ The liver stiffness measurement (LSM) of a normal liver is $<5.5 \mathrm{kPa}$, with values ranging up to $75 \mathrm{kPa}$ in disease. ${ }^{71}$ Myriad studies have explored the use of VCTE in patients with NAFLD, with data derived from both Asian and Western series in addition to adult and pediatric cohorts. Based on these studies, variable LSM cut-off values for each stage of fibrosis have been reported, with readings of 6.6-7.8, 7.1-10.4 and $10.3-22.3 \mathrm{kPa}$ corresponding to stages F2, F3 and F4 respectively. ${ }^{72}$ However, there remains no universal consensus on which cut-off value to use.

In NAFLD, LSM by VCTE has been shown to have good diagnostic accuracy for the presence of fibrosis, with an 
Cheah M.C.C. et al: Fibrosis assessment in NAFLD

Table 1. Summary of non-invasive scoring systems based on biochemical markers in NAFLD/NASH

\begin{tabular}{|c|c|c|c|c|}
\hline Score & Components & Formula & AUROC & $\begin{array}{l}\text { Cut-off values for advanced } \\
\text { fibrosis }\end{array}$ \\
\hline $\begin{array}{l}\text { NAFLD fibrosis } \\
\text { score }(\text { NFS) })^{12,37,38}\end{array}$ & $\begin{array}{l}\text { - Age } \\
\text { - Hyperglycemia } \\
\text { - BMI } \\
\text { - Platelet count } \\
\text { - Albumin } \\
\text { - AST/ALT ratio }\end{array}$ & $\begin{array}{l}\text { NFS }=-1.675+0.037 \times \text { age } \\
(\text { years })+0.094 \times \text { BMI }\left(\mathrm{kg} / \mathrm{m}^{2}\right) \\
+1.13 \times \text { IFG } / \text { diabetes }(\mathrm{yes}=1 \\
\text { no }=0)+0.99 \times \text { AST/ALT ratio }- \\
0.013 \times \text { platelet } \\
\left(\times 10^{9} / \mathrm{L}\right)-0.66 \times \\
\text { albumin }(\mathrm{g} / \mathrm{dL})\end{array}$ & $0.81-0.85$ & $\begin{array}{l}\text { NFS }<-1.455=F 0-F 2 \\
\text { NFS: } 1.455-0.675= \\
\text { indeterminate NFS }> \\
0.675=\mathrm{F} 3-\mathrm{F} 4\end{array}$ \\
\hline FibroTest $^{\circledR 43}$ & $\begin{array}{l}\text { - Bilirubin } \\
\text { - GGT } \\
\text { - } \alpha 2 \text {-macroglobulin } \\
\text { - Haptoglobin } \\
\text { - Apolipoprotein A1 }\end{array}$ & Proprietary formula & 0.86 & $\begin{array}{l}\text { Fibrotest }>0.30 \text { : } \\
\text { Advanced fibrosis ( } \geq F 3 \text { ) }\end{array}$ \\
\hline APRI $^{37,44,46,47}$ & $\begin{array}{l}\text { - AST } \\
\text { - Platelets }\end{array}$ & $\begin{array}{l}\text { APRI }=[\text { AST/AST }(\text { ULN })] / \\
\text { platelet }\left(\times 10^{9} / \mathrm{L}\right)\end{array}$ & $0.67-0.78$ & $\begin{array}{l}\text { APRI }>1 \text { : Advanced } \\
\text { fibrosis }(\geq \mathrm{F} 3)\end{array}$ \\
\hline FIB- $4{ }^{47,55}$ & $\begin{array}{l}\text { - Age } \\
\text { - AST } \\
\text { - ALT } \\
\text { - Platelets }\end{array}$ & $\begin{array}{l}\text { FIB-4 }=(\text { age }(\text { years }) \times \text { AST } \\
(I U / L)) /((P L T[109 / L]) \times \\
\left.(A L T(I U / L))^{2}\right)\end{array}$ & $0.80-0.82$ & $\begin{array}{l}\text { FIB-4 < 1.30: F0-F1FIB-4 > } \\
\text { 2.67: Advanced fibrosis } \\
(\geq \mathrm{F} 3)\end{array}$ \\
\hline BAAT $^{55,56}$ & $\begin{array}{l}\text { - BMI } \\
\text { - Age } \\
\text { - ALT } \\
\text { - Triglycerides }\end{array}$ & $\begin{array}{l}\text { Weighted sum of: } \mathrm{B}: \mathrm{BMI} \geq \\
\quad 28=1 \\
\text { A: Age } \geq 50 \text { yrs }=1 \\
\text { A: ALT } \geq 2 \mathrm{~N}=1 \\
\text { T: Triglycerides } \geq 1.7 \mathrm{mmol} / \mathrm{L}=1\end{array}$ & $0.67-0.84$ & $\begin{array}{l}\text { BAAT > 2.86: Advanced } \\
\text { fibrosis }(\geq \mathrm{F} 3)\end{array}$ \\
\hline BARD score ${ }^{57-59}$ & $\begin{array}{l}\text { - } \mathrm{BMI} \\
\text { - } \mathrm{AST} / \mathrm{ALT} \text { ratio } \\
\text { - } \mathrm{DM}\end{array}$ & $\begin{array}{l}\text { Weighted sum of: } B: B M I \geq 28= \\
1 \text { point, } \\
\text { AAR: } A S T / A L T \text { ratio } \geq 0.8=2 \text {, } \\
\text { DM }=1 \text { point }\end{array}$ & $0.67-0.87$ & $\begin{array}{l}\text { BARD score }>2 \text { : Advanced } \\
\text { fibrosis }(\geq \mathrm{F} 3 \text { ) }\end{array}$ \\
\hline $\mathrm{ELF}^{63}$ & $\begin{array}{l}\text { - P3NP } \\
\text { - TIMP-1 } \\
\text { - Hyaluronic acid }\end{array}$ & $\begin{array}{l}\mathrm{ELF}=-7.412+(\operatorname{In}(\mathrm{HA}) * 0.681) \\
+(\operatorname{In}(\mathrm{P} 3 \mathrm{NP}) * 0.775) \\
+(\operatorname{In}(\mathrm{TIMP}-1) * 0.494)\end{array}$ & 0.90 & $\begin{array}{l}\text { ELF > 0.3576: Advanced } \\
\text { fibrosis }(\geq \mathrm{F} 3)\end{array}$ \\
\hline $\begin{array}{l}\text { FibroMeter for } \\
\text { NAFLD }\end{array}$ & $\begin{array}{l}\text { - Age } \\
\text { - Body weight } \\
\text { - Glycemia } \\
\text { - Platelets } \\
\text { - AST } \\
\text { - ALT } \\
\text { - Ferritin }\end{array}$ & $\begin{array}{l}0.4184 \text { glucose }[\mathrm{mmol} / \mathrm{L}]+ \\
0.0701 \mathrm{AST}[\mathrm{U} / \mathrm{L}]+0.00008 \\
\text { ferritin }[\mu \mathrm{g} / \mathrm{L}]-0.0102 \text { platelet } \\
{[\mathrm{g} / \mathrm{L}]-0.0260 \mathrm{ALT}[\mathrm{U} / \mathrm{L}]+} \\
0.0459 \text { body weight }[\mathrm{kg}]+ \\
0.0842 \text { age }[\text { years }+11.6226\end{array}$ & 0.94 & $\begin{array}{l}\text { FibroMeter for NAFLD > } \\
0.49: \text { Significant fibrosis } \\
(\geq F 2)\end{array}$ \\
\hline
\end{tabular}

Abbreviations: ALT, alanine transaminase; AST, aspartate transaminase; APRI, AST platelet ratio index; BAAT, BMI, age, ALT, triglycerides; BARD, BMI, AST/ALT ratio, DM; AUROC, area under receiver operating characteristic curve; BMI, body mass index; DM, diabetes mellitus; ELF, enhanced liver fibrosis; GGT, gamma-glutamyl transpeptidase; HA, hyaluronic acid; IFG, impaired fasting glucose; P3NP, procollagen $3 \mathrm{~N}$-terminal peptide; TIMP-1, tissue inhibitors of metalloproteinase-1.

AUROC of 0.927 for $\geq F 1$ fibrosis. ${ }^{73,74}$ An excellent AUROC of 0.93 (95\% CI 0.89-0.096) has been reported for advanced fibrosis $(\geq F 3)$ and cirrhosis, with a negative predictive value of $90 \%$ in ruling out cirrhosis when using a cut-off of LSM $7.9 \mathrm{kPa}{ }^{75}$ In a meta-analysis of 1047 patients, the pooled sensitivities and specificities for VCTE to diagnosis $\geq F 2$, $\geq F 3$ and $F 4$ disease were $79 \%$ and $75 \%, 85 \%$ and $85 \%, 92 \%$ and $92 \%$ respectively. ${ }^{76}$ However, the utility of differentiating between F2 and F3 fibrosis seems less robust. ${ }^{75}$ The strength of VCTE, therefore, lies in its use as a good screening tool to: i) rule out the presence of fibrosis, and ii) differentiate advanced fibrosis $(\geq F 3)$ and cirrhosis from earlier stages of fibrosis.

However, VCTE is not without shortcomings. Steatosis and hepatocellular necroinflammation has been reported to cause falsely elevated readings of LSM. ${ }^{77-80}$ One study reported the correlation of hepatic steatosis as quantified by controlled attenuation parameter (CAP), with increased LSM-graded fibrosis that may be attributed to steatosis resulting in discordance with fibrosis graded by paired liver biopsy samples. ${ }^{81}$ The authors recommend using CAP-graded steatosis to determine the likelihood of a falsely elevated LSM fibrosis grade that may be attributed to steatosis, and if the likelihood is high, to consider using a higher LSM cutoff. The impact of increased hepatic steatosis on falsely elevated LSM remains to be clarified. Further, cholestasis, increased central venous pressure and recent food intake (within 60 mins) have all been reported to falsely raise LSM. ${ }^{82-84}$ Importantly, increased BMI $>30 \mathrm{~kg} / \mathrm{m}^{2}$ has been reported to be independent predictors of failed 
LSM in up to $25 \%$ of attempted studies with the conventional $M$ probe. ${ }^{85,86}$

The $\mathrm{XL}$ probe attempts to circumvent issues with the $M$ probe with the intent of improving the rate of successful LSM studies. The XL probe has a greater depth of measurement below the skin surface and features a lower frequency, more sensitive transducer with a larger vibration amplitude and deeper focal length. ${ }^{87}$ In one study, the use of the $\mathrm{XL}$ probe allowed reliable LSM measurements in $92 \%$ of patients compared with $80 \%$, when using the M probe alone. ${ }^{88}$ In a study of 193 consecutive patients, evaluating the performance of the $\mathrm{XL}$ probe and $\mathrm{M}$ probe with paired liver biopsies, the $\mathrm{XL}$ probe was more likely than the $M$ probe to achieve success ( $95 \%$ vs $81 \% \mathrm{P}<0.001$ ). At a cut-off of $7.2 \mathrm{kPa}$ for advanced fibrosis ( $\geq F 3$ ), sensitivity was $78 \%$, specificity was $78 \%$, positive predictive value $60 \%$ and negative predictive value of $89 \%$, with an AUROC of 0.85 , was reported. ${ }^{89}$ However, discordance by up to two stages between the XL probe and histology in $9 \%$ of patients was also noted in this study. Other studies have also reported that the median LSM by the XL probe was $1-1.2 \mathrm{kPa}$ lower than that measured by the M probe, for the same stage of fibrosis. ${ }^{88,89}$

\section{MRE}

MRE is a highly accurate modality for estimating liver stiffness that can be easily supplemented to routine magnetic resonance imaging (MRI) protocols. Acoustic drivers are used to generate continuous vibrations at $60 \mathrm{~Hz}$, which are transmitted through the liver. The resulting propagating shear waves in the liver are then captured using a MRI sequence with motion-encoding gradient. ${ }^{90}$ MRE readings are uniquely advantaged in not being affected by obesity, simple steatosis or the presence of ascites. ${ }^{90-92}$ In a retrospective cohort study of 325 patients with NAFLD, MRE with a cut-off of $4.15 \mathrm{kPa}$ was able to identify patients with advanced fibrosis ( $\geq$ F3) with an AUROC of 0.954 , sensitivity of 0.85 , and specificity of $0.929 .{ }^{93}$ In a systematic review evaluating nine studies (232 patients with NAFLD), Singh et al. ${ }^{94}$ demonstrated the high diagnostic accuracy of MRE for detection of fibrosis in NAFLD, with the mean AUROC for detecting any $(\geq F 1)$, significant ( $\geq F 2)$, advanced fibrosis ( $\geq F 3$ ) and cirrhosis (F4) of $0.86(0.82-0.90), 0.87(0.82-0.93), 0.90$ (0.84$0.94)$ and $0.91(0.76-0.95)$ respectively. The performance of MRE was not affected by sex, obesity or degree of inflammation. ${ }^{94}$ In addition, MRE was found to have higher diagnostic performance compared to transient elastography in two recent separate cross-sectional studies from Japan and the United States. ${ }^{95,96}$ Along similar lines, MRE was also more accurate than acoustic resonance force impulse (ARFI) for diagnosing any fibrosis $(F \geq 1)$ in NAFLD patients. ${ }^{97}$

To further optimize performance, 3-dimensional (3-D) MRE, a novel variation of the standard, commercially available MRE, which utilized 2-dimensional (2-D) technology, was explored. Using a cohort of patients with biopsy-proven NAFLD, Loomba and colleagues ${ }^{98}$ demonstrated that 3-D MRE (shear wave frequency of $40 \mathrm{~Hz}$ ) had even better diagnostic accuracy for identifying advanced fibrosis compared to 2-D MRE (shear wave frequency of $60 \mathrm{~Hz}$ ) (AUROC $0.981 \mathrm{vs}$ $0.921, p<0.05)$.

MRE represents an excellent and highly accurate modality for assessing LSM in NAFLD that is operator-independent, not affected by obesity or ascites, and is also complemented by the ability to obtain anatomical MR imaging at the same time.
However, it is dependent on patient factors such as inability to perform breath-hold, and signal degradation in patients with severe iron overload. Similarly, it may not be feasible as a screening tool with considerations for widespread use in view of limitations of facility constraints, high cost and longer examination time, as opposed to VCTE, which can provide the convenience of a rapid bedside procedure that can provide immediate results to the physician.

\section{ARFI}

ARFI is an elastography technique developed by Siemens using modified commercially available ultrasound machines, integrating both elastography and conventional B-mode ultrasonography. By using conventional ultrasound, the operator is able to avoid large blood vessels and other anatomic confounders of LSM. After targeting a $5 \mathrm{~mm} \times 10 \mathrm{~mm}$ area of interest, the AFRI probe is used to produce short $262 \mathrm{~ms}$ pulses at $2.67 \mathrm{MHz}$ to generate shear waves, propagation of which is tracked by ultrasound to produce the metric of shear wave speed as a surrogate of fibrosis.

In a cohort of 250 consecutive patients with paired liver biopsies, ARFI was able to predict $\geq F 2$ fibrosis and cirrhosis (F4) with an AUROC of 0.74 (95\% CI: 0.64-0.86) and 0.79 (95\% CI: $0.67-0.91$ ) respectively. ${ }^{99}$ A meta-analysis of seven studies involving 723 patients reported a pooled sensitivity of $80.2 \%$ and specificity of $85.2 \%$ in detecting significant fibrosis as defined by stage 2 or more fibrosis, for which the authors concluded that ARFI was modestly accurate in detecting significant fibrosis in NAFLD. ${ }^{99}$ In a comparative study of Fibroscan ${ }^{\circledR}$ versus AFRI in 291 NAFLD who underwent liver biopsies, similarly good accuracies were reported for AUROC for advanced fibrosis ( $\geq F 3$ ), reported as 0.87 and 0.85 for Fibroscan ${ }^{\circledR}$ and AFRI respectively. ${ }^{101}$ Similarly, in a metaanalysis comparing the performance of ARFI and VCTE, no difference in performance was found in the detection of significant fibrosis or cirrhosis. ${ }^{102}$

One advantage of ARFI is that it is not affected by morbid obesity (BMI >40). However, the role of ARFI in NAFLD remains to be clarified. ${ }^{103}$

\section{Supersonic shearwave imaging (SSI)}

SSI, otherwise known as shearwave elastography, was developed by SuperSonic Imagine (S.A, Aix-en-Provence, France). It allows acquisition of liver stiffness in real-time, whilst guided by a B-mode image. ${ }^{104}$ It is similar to ARFI in being ultrasound based, without the need of an external vibrator to produce the shear wave. However, whilst ARFI measures a single shear wave emitted at a single frequency, the transducer in SSI emits a spectrum of pulsed wave beams of varied depths using a frequency band ranging from 60 to $600 \mathrm{~Hz}$. This allows for a near simultaneous evaluation of several shear wave fronts over a wide frequency range. ${ }^{105-107}$ Cassinoto et al. ${ }^{108}$ conducted a comparative study of SSI, ARFI and Fibroscan $^{\circledR}$ for assessment of liver fibrosis in a cohort of mixed etiology patients undergoing liver biopsy; SSI performed well, with an AUROC of 0.92 (95\% CI: 0.89-0.95) with a specificity and sensitivity of $90 \%$ and $81 \%$ for advanced fibrosis ( $\geq F 3$ ). In this study, SSI compared favorably to Fibroscan ${ }^{\circledR}$ for the diagnosis of advanced fibrosis with an accuracy of $84 \%$ vs $78 \%(p=0.0016)$. In another comparative study of SSI, AFRI and Fibroscan ${ }^{\circledR}$ in patients with NAFLD ( $n=291$ ) undergoing liver biopsy, no difference was seen 
Cheah M.C.C. et al: Fibrosis assessment in NAFLD

Table 2. Imaging-based assessment of fibrosis in NASH

\begin{tabular}{|c|c|c|c|c|}
\hline Modality & Parameter assessed & $\begin{array}{l}\text { Cut-off values for } \\
\text { advanced fibrosis }\end{array}$ & AUROC & Comment \\
\hline $\begin{array}{l}\text { Transient } \\
\text { elastography } \\
(\text { VCTE })^{74,75,101}\end{array}$ & $\begin{array}{l}\text { LSM using assessment of } \\
\text { shear wave velocity }\end{array}$ & $\begin{array}{l}\text { Fibroscan }^{\circledR} \\
\text { LSM: }<7.9 \mathrm{kPa} \text { (in } \\
\text { NAFLD): } \\
\text { No advanced fibrosis } \\
\text { LSM: }>9.6 \mathrm{kPa} \text { (in } \\
\text { NAFLD): } \\
\text { Advanced fibrosis }\end{array}$ & $0.82-0.93$ & $\begin{array}{l}\text { - Cheap } \\
\text { - Reproducible } \\
\text { - Use of XL probe may under- } \\
\text { report LSM }\end{array}$ \\
\hline $\begin{array}{l}\text { Magnetic } \\
\text { resonance } \\
\text { elastography } \\
(\mathrm{MRE})^{93,94}\end{array}$ & $\begin{array}{l}\text { LSM by shear wave } \\
\text { measurement using MRI } \\
\text { sequence with motion } \\
\text { encoding gradient }\end{array}$ & $\begin{array}{l}\text { MRE LSM: >4.15 kPa: } \\
\text { Advanced fibrosis }\end{array}$ & $0.90-0.95$ & $\begin{array}{l}\text { - Expensive } \\
\text { - Allows opportunistic assess- } \\
\text { ment of LSM during MRI } \\
\text { - Mitigates issues of obesity or } \\
\text { presence of ascites }\end{array}$ \\
\hline $\begin{array}{l}\text { Acoustic resonance } \\
\text { force impulse } \\
(\text { AFRI })^{99,102}\end{array}$ & $\begin{array}{l}\text { LSM integrating } \\
\text { elastography and } \\
\text { conventional B-mode } \\
\text { ultrasonography }\end{array}$ & $\begin{array}{l}\text { AFRI }>1.98 \mathrm{~m} / \mathrm{s} \text { for } \\
\text { F4 }\end{array}$ & $0.74-0.85$ & $\begin{array}{l}\text { - Cheap } \\
\text { - Uses conventional ultra- } \\
\text { sound machines with modi- } \\
\text { fied algorithm }\end{array}$ \\
\hline $\begin{array}{l}\text { Supersonic } \\
\text { shearwave } \\
\text { imaging } \\
(\mathrm{SSI})^{101,108}\end{array}$ & $\begin{array}{l}\text { LSM integrating } \\
\text { elastography and } \\
\text { conventional B-mode } \\
\text { ultrasonography with } \\
\text { simultaneous assessment of } \\
\text { several shear waves of } \\
\text { different velocity }\end{array}$ & SSI LSM > $8.3 \mathrm{kPa}$ & $0.83-0.92$ & $\begin{array}{l}\text { - Cheap } \\
\text { - Slightly higher reported } \\
\text { accuracy for SSI for } \\
\text { advanced fibrosis when } \\
\text { compared with Fibroscan }{ }^{\circledR}\end{array}$ \\
\hline
\end{tabular}

Abbreviations: AUROC, area under receiver operating characteristic curve; LSM, liver stiffness measurement.

in accuracy between the modalities for detecting advanced fibrosis $(\geq \mathrm{F} 3)$, with AUROC for SSI, Fibroscan ${ }^{\circledR}$ and ARFI being $0.89,0.86$ and 0.84 respectively. ${ }^{101}$ However, with regards to significant fibrosis ( $\geq$ F2), SSI, while comparable to Fibroscan ${ }^{\circledR}$, had a higher accuracy than ARFI for diagnosis of significant fibrosis $(p=0.004)$.

\section{Summary of elastography-based assessments of fibrosis}

VCTE has been widely adopted as a reliable means of assessing NAFLD patients for advanced fibrosis ${ }^{75,76}$ and has been extensively studied in both Asian and Western cohorts. ${ }^{72}$ Some shortcomings are noted, however, especially with steatosis potentially falsely elevating LSM reading, ${ }^{81}$ in addition to the $X \mathrm{~L}$ probe having a potential discordance in LSM readings when compared to the M probe. ${ }^{88,89}$ Nonetheless, VCTE remains a relatively robust and reliable tool that has already been widely used in clinical practice for the assessment of fibrosis.

Newer ultrasound-based modalities that capitalize on inherent B-mode ultrasonography, such as ARFI and SSI, represent an opportunity to serendipitously assess fibrosis in NAFLD patients undergoing ultrasonography, and shows good performance in comparative studies with VCTE. ${ }^{101,102,108}$ More data needs to be demonstrated, particularly in the context of correlation to clinically relevant outcomes.

Separately, MRE, whilst having numerous advantages, including being unaffected by obesity, simple steatosis, inflammation or the presence of ascites, ${ }^{90-92,94}$ is largely limited by high cost and accessibility. MRE will probably remain as an opportunistic adjunct for assessment of fibrosis in NAFLD patients undergoing MRI for other reasons. A summary of the elastography-based assessments of fibrosis is available in Table 2.

\section{Perspectives on clinical application}

In day-to-day clinical practice, there have not been any universally accepted algorithms in diagnosis and approach to fibrosis in the context of NAFLD, mainly because no noninvasive modality, either alone or in combination, has been shown to be consistently robust. Among the major society guidelines, the EASL guidelines do suggest that a combination of modality may perform better than a single modality alone. However, there is no robust longitudinal data to correlate the utility of combined modality and clinically relevant outcomes. In our own practice, we commonly utilize a combination of NFS and VCTE in the assessment of advanced fibrosis for patients with NAFLD, as shown in Fig. 1. This has been highlighted before in several other publications advocating its use. ${ }^{109}$ Moreover, this approach was demonstrated by Petta et al., ${ }^{110}$ who compared various bedside scoring systems, such as the APRI, AST/ALT, BARD, FIB-4 and NFS scores, in combination with VCTE. In the validation cohort, the combination of NFS and VCTE had an excellent AUC of 0.844 , a specificity of $100 \%$, a positive predictive value of $100 \%$ and a negative predictive value of $92.7 \%$ for advanced fibrosis $(\geq F 3$ ). In addition, this combination not only provides excellent performance but also represents a cost-effective strategy as demonstrated by Tapper et al. ${ }^{111}$ 
Cheah M.C.C. et al: Fibrosis assessment in NAFLD

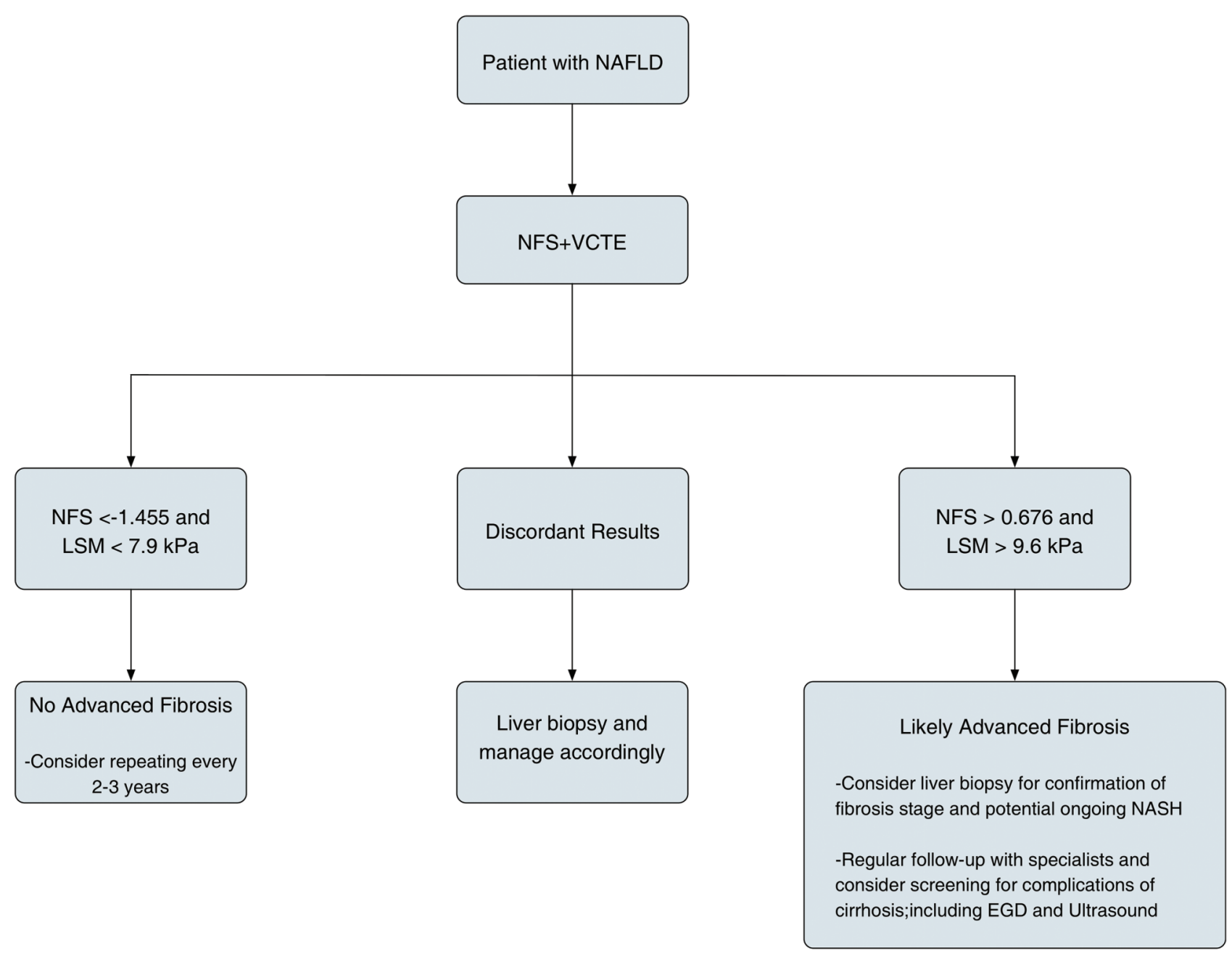

Fig. 1. Proposed algorithm for assessing NAFLD patients for advanced fibrosis. ${ }^{109}$

\section{Conclusions}

Whilst liver biopsy remains the gold standard in assessing necroinflammation and fibrosis to prognosticate patients with NAFLD, it remains far from ideal, with inherent issues of safety and sampling error. Recent years have seen the proliferation of various methods that are able to accurately assess necroinflammation and fibrosis, and allow for viable alternatives to liver biopsy. This is especially important when considering that serial assessments are required over the course of a patient's lifetime to gauge progression of disease, decide on intervention and track response to treatment. Bedsides, scoring systems such as NFS, FIB-4 and APRI are easily calculated using commonly available parameters and are helpful tools to allow the clinician to identify patients with advanced fibrosis. Methods to assess LSM, such as Fibroscan ${ }^{\circledR}$, have gained popularity in being highly accurate and reproducible, to assess the presence of fibrosis and detect advanced disease. However, a majority of the non-invasive tests are less nuanced and not as reliable to differentiate between early stages of fibrosis (F1 to F2). The role, therefore, of liver biopsy in this current era is to obtain definitive proof of $\mathrm{NASH}$, especially in patients with competing concomitant diagnoses, such as chronic hepatitis B, and to allow assessment of early fibrosis when noninvasive methods are unable to provide adequate resolution.

\section{Conflict of interest}

The authors have no conflict of interests related to this publication.

\section{Author contributions}

Involved with collection and analysis of data, manuscript writing, critical revision and approval of the final manuscript (MCCC), involved with conception of study objectives and design, interpretation of data, manuscript writing and critical revision and approval of the final manuscript (AJM), involved with conception of study objectives and design, interpretation of data, manuscript writing and critical revision and approval of the final manuscript (GBBG).

\section{References}

[1] Younossi ZM, Koenig AB, Abdelatif D, Fazel Y, Henry L, Wymer M. Global epidemiology of nonalcoholic fatty liver disease-Meta-analytic assessment 
of prevalence, incidence, and outcomes. Hepatology 2016;64:73-84. doi: 10.1002/hep.28431.

[2] Farrell GC, Wong VW, Chitturi S. NAFLD in Asia-as common and important as in the West. Nat Rev Gastroenterol Hepatol 2013;10:307-318. doi: 10. 1038/nrgastro.2013.34

[3] Loomba R, Sanyal AJ. The global NAFLD epidemic. Nat Rev Gastroenterol Hepatol 2013;10:686-690. doi: 10.1038/nrgastro.2013.171.

[4] Liu H, Lu HY. Nonalcoholic fatty liver disease and cardiovascular disease. World J Gastroenterol 2014;20:8407-8415. doi: 10.3748/wjg.v20.i26. 8407.

[5] Ekstedt M, Franzén LE, Mathiesen UL, Thorelius L, Holmqvist M, Bodemar G, et al. Long-term follow-up of patients with NAFLD and elevated liver enzymes. Hepatology 2006;44:865-873. doi: 10.1002/hep.21327.

[6] Younossi ZM, Blissett D, Blissett R, Henry L, Stepanova M, Younossi Y, et al. The economic and clinical burden of nonalcoholic fatty liver disease in the United States and Europe. Hepatology 2016;64:1577-1586. doi: 10.1002/ hep. 28785.

[7] Goh GB, McCullough AJ. Natural history of nonalcoholic fatty liver disease. Dig Dis Sci 2016;61:1226-1233. doi: 10.1007/s10620-016-4095-4.

[8] Dyson J, Jaques B, Chattopadyhay D, Lochan R, Graham J, Das D, et al. Hepatocellular cancer: the impact of obesity, type 2 diabetes and a multidisciplinary team. J Hepatol 2014;60:110-117. doi: 10.1016/j.jhep.2013. 08.011.

[9] Adams LA, Lymp JF, St Sauver J, Sanderson SO, Lindor KD, Feldstein A, et al. The natural history of nonalcoholic fatty liver disease: a population-based cohort study. Gastroenterology 2005;129:113-121. doi: 10.1053/j.gastro. 2005.04.014.

[10] Ong JP, Pitts A, Younossi ZM. Increased overall mortality and liver-related mortality in non-alcoholic fatty liver disease. J Hepatol 2008;49:608-612. doi: 10.1016/j.jhep.2008.06.018.

[11] Rafiq N, Bai C, Fang Y, Srishord M, McCullough A, Gramlich T, et al. Longterm follow-up of patients with nonalcoholic fatty liver. Clin Gastroenterol Hepatol 2009;7:234-238. doi: 10.1016/j.cgh.2008.11.005.

[12] Musso G, Gambino R, Cassader M, Pagano G. Meta-analysis: natural history of non-alcoholic fatty liver disease (NAFLD) and diagnostic accuracy of noninvasive tests for liver disease severity. Ann Med 2011;43:617-649. doi: 10.3109/07853890.2010.518623.

[13] Spengler EK, Loomba R. Recommendations for diagnosis, referral for liver biopsy, and treatment of nonalcoholic fatty liver disease and nonalcoholic steatohepatitis. Mayo Clin Proc 2015;90:1233-1246. doi: 10.1016/j. mayocp.2015.06.013.

[14] Kleiner DE, Brunt EM, Van Natta M, Behling C, Contos MJ, Cummings OW, et al. Design and validation of a histological scoring system for nonalcoholic fatty liver disease. Hepatology 2005;41:1313-1321. doi: 10.1002/hep. 20701.

[15] Sanyal AJ, Brunt EM, Kleiner DE, Kowdley KV, Chalasani N, Lavine JE, et al. Endpoints and clinical trial design for nonalcoholic steatohepatitis. Hepatology 2011;54:344-353. doi: 10.1002/hep.24376.

[16] Ekstedt M, Hagström H, Nasr P, Fredrikson M, Stål P, Kechagias S, et al. Fibrosis stage is the strongest predictor for disease-specific mortality in NAFLD after up to 33 years of follow-up. Hepatology 2015;61:15471554. doi: 10.1002/hep. 27368 .

[17] Angulo P, Kleiner DE, Dam-Larsen S, Adams LA, Bjornsson ES, Charatcharoenwitthaya $\mathrm{P}$, et al. Liver fibrosis, but no other histologic features, is associated with long-term outcomes of patients with nonalcoholic fatty liver disease. Gastroenterology 2015;149:389-397.e10. doi: 10.1053/j. gastro.2015.04.043

[18] Younossi ZM, Stepanova M, Rafiq N, Makhlouf H, Younoszai Z, Agrawal R, et al. Pathologic criteria for nonalcoholic steatohepatitis: interprotocol agreement and ability to predict liver-related mortality. Hepatology 2011; 53:1874-1882. doi: 10.1002/hep.24268.

[19] Skelly MM, James PD, Ryder SD. Findings on liver biopsy to investigate abnormal liver function tests in the absence of diagnostic serology. J Hepatol 2001;35:195-199. doi: 10.1016/S0168-8278(01)00094-0.

[20] Kleiner DE, Brunt EM. Nonalcoholic fatty liver disease: pathologic patterns and biopsy evaluation in clinical research. Semin Liver Dis 2012;32:3-13. doi: $10.1055 / \mathrm{s}-0032-1306421$

[21] Kleiner DE, Makhlouf HR. Histology of nonalcoholic fatty liver disease and nonalcoholic steatohepatitis in adults and children. Clin Liver Dis 2016;20: 293-312. doi: 10.1016/j.cld.2015.10.011.

[22] Brunt EM, Janney CG, Di Bisceglie AM, Neuschwander-Tetri BA, Bacon BR. Nonalcoholic steatohepatitis: a proposal for grading and staging the histological lesions. Am J Gastroenterol 1999;94:2467-2474. doi: 10.1111/j. 1572-0241.1999.01377.x.

[23] Bedossa P, Poitou C, Veyrie N, Bouillot JL, Basdevant A, Paradis V, et al. Histopathological algorithm and scoring system for evaluation of liver lesions in morbidly obese patients. Hepatology 2012;56:1751-1759. doi: 10.1002/hep.25889.

[24] Bedossa P. Pathology of non-alcoholic fatty liver disease. Liver Int 2017;37 Suppl 1:85-89. doi: 10.1111/liv.13301.
[25] Brunt EM. Pathology of nonalcoholic fatty liver disease. Nat Rev Gastroenterol Hepatol 2010;7:195-203. doi: 10.1038/nrgastro.2010.21.

[26] Piccinino F, Sagnelli E, Pasquale G, Giusti G. Complications following percutaneous liver biopsy. A multicentre retrospective study on 68,276 biopsies. J Hepatol 1986;2:165-173. doi: 10.1016/S0168-8278(86)80075-7.

[27] Bonekamp S, Tang A, Mashhood A, Wolfson T, Changchien C, Middleton MS, et al. Spatial distribution of MRI-Determined hepatic proton density fat fraction in adults with nonalcoholic fatty liver disease. J Magn Reson Imaging 2014;39:1525-1532. doi: 10.1002/jmri.24321.

[28] Merriman RB, Ferrell LD, Patti MG, Weston SR, Pabst MS, Aouizerat BE, et al. Correlation of paired liver biopsies in morbidly obese patients with suspected nonalcoholic fatty liver disease. Hepatology 2006;44:874-880. doi: $10.1002 /$ hep. 21346 .

[29] Larson SP, Bowers SP, Palekar NA, Ward JA, Pulcini JP, Harrison SA. Histopathologic variability between the right and left lobes of the liver in morbidly obese patients undergoing Roux-en-Y bypass. Clin Gastroenterol Hepatol 2007; 5:1329-1332. doi: 10.1016/j.cgh.2007.06.005.

[30] Ratziu V, Charlotte F, Heurtier A, Gombert S, Giral P, Bruckert E, et al. Sampling variability of liver biopsy in nonalcoholic fatty liver disease. Gastroenterology 2005;128:1898-1906. doi: 10.1053/j.gastro.2005.03.084.

[31] Younossi ZM, Gramlich T, Liu YC, Matteoni C, Petrelli M, Goldblum J, et al. Nonalcoholic fatty liver disease: assessment of variability in pathologic interpretations. Mod Pathol 1998;11:560-565.

[32] Takahashi Y, Fukusato T. Histopathology of nonalcoholic fatty liver disease/nonalcoholic steatohepatitis. World J Gastroenterol 2014;20:1553915548. doi: $10.3748 /$ wjg.v20.i42.15539.

[33] Mofrad $P$, Contos MJ, Haque M, Sargeant C, Fisher RA, Luketic VA, et al. Clinical and histologic spectrum of nonalcoholic fatty liver disease associated with normal ALT values. Hepatology 2003;37:1286-1292. doi: 10.1053/ jhep.2003.50229.

[34] Verma S, Jensen D, Hart J, Mohanty SR. Predictive value of ALT levels for non-alcoholic steatohepatitis (NASH) and advanced fibrosis in non-alcoholic fatty liver disease (NAFLD). Liver Int 2013;33:1398-1405. doi: 10.1111/ liv. 12226.

[35] Chalasani N, Younossi Z, Lavine JE, Diehl AM, Brunt EM, Cusi K, et al. The diagnosis and management of non-alcoholic fatty liver disease: practice Guideline by the American Association for the Study of Liver Diseases, American College of Gastroenterology, and the American Gastroenterological Association. Hepatology 2012;55:2005-2023. doi: 10.1002/hep. 25762.

[36] European Association for Study of Liver; Asociacion Latinoamericana para el Estudio del Higado. EASL-ALEH Clinical Practice Guidelines: Non-invasive tests for evaluation of liver disease severity and prognosis. J. Hepatol 2015;63:237-264. doi: 10.1016/j.jhep.2015.04.006.

[37] McPherson S, Stewart SF, Henderson E, Burt AD, Day CP. Simple non-invasive fibrosis scoring systems can reliably exclude advanced fibrosis in patients with non-alcoholic fatty liver disease. Gut 2010;59:1265-1269. doi: 10.1136/gut.2010.216077.

[38] Angulo P, Hui JM, Marchesini G, Bugianesi E, George J, Farrell GC, et al. The NAFLD fibrosis score: a noninvasive system that identifies liver fibrosis in patients with NAFLD. Hepatology 2007;45:846-854. doi: 10.1002/hep. 21496.

[39] Kim D, Kim WR, Kim HJ, Therneau TM. Association between noninvasive fibrosis markers and mortality among adults with nonalcoholic fatty liver disease in the United States. Hepatology 2013;57:1357-1365. doi: 10. 1002/hep.26156.

[40] Treeprasertsuk S, Björnsson E, Enders F, Suwanwalaikorn S, Lindor KD. NAFLD fibrosis score: a prognostic predictor for mortality and liver complications among NAFLD patients. World J Gastroenterol 2013;19:12191229. doi: $10.3748 /$ wjg.v19.i8.1219.

[41] Wong VW, Wong GL, Chim AM, Tse AM, Tsang SW, Hui AY, et al. Validation of the NAFLD fibrosis score in a Chinese population with low prevalence of advanced fibrosis. Am J Gastroenterol 2008;103:1682-1688. doi: 10. 1111/j.1572-0241.2008.01933.x.

[42] Myers RP, Benhamou Y, Imbert-Bismut $F$, Thibault V, Bochet M, Charlotte $F$, et al. Serum biochemical markers accurately predict liver fibrosis in HIV and hepatitis C virus co-infected patients. AIDS 2003;17:721-725. doi: 10 . 1097/01.aids.0000050827.06065.16.

[43] Ratziu V, Massard J, Charlotte F, Messous D, Imbert-Bismut F, Bonyhay L, et al. Diagnostic value of biochemical markers (FibroTest-FibroSURE) for the prediction of liver fibrosis in patients with non-alcoholic fatty liver disease. BMC Gastroenterol 2006;6:6. doi: 10.1186/1471-230X-6-6.

[44] Wai CT, Greenson JK, Fontana RJ, Kalbfleisch JD, Marrero JA, Conjeevaram $\mathrm{HS}$, et al. A simple noninvasive index can predict both significant fibrosis and cirrhosis in patients with chronic hepatitis C. Hepatology 2003;38: 518-526. doi: 10.1053/jhep.2003.50346.

[45] Tapper EB, Krajewski K, Lai M, Challies T, Kane R, Afdhal N, et al. Simple non-invasive biomarkers of advanced fibrosis in the evaluation of nonalcoholic fatty liver disease. Gastroenterol Rep (Oxf) 2014;2:276-280. doi: $10.1093 /$ gastro/gou034. 
[46] Adams LA, George J, Bugianesi E, Rossi E, De Boer WB, van der Poorten D, et al. Complex non-invasive fibrosis models are more accurate than simple models in non-alcoholic fatty liver disease. J Gastroenterol Hepatol 2011; 26:1536-1543. doi: 10.1111/j.1440-1746.2011.06774.x.

[47] Shah AG, Lydecker A, Murray K, Tetri BN, Contos MJ, Sanyal AJ, et al. Comparison of noninvasive markers of fibrosis in patients with nonalcoholic fatty liver disease. Clin Gastroenterol Hepatol 2009;7:1104-1112. doi: 10.1016/ j.cgh.2009.05.033.

[48] Sheth SG, Flamm SL, Gordon FD, Chopra S. AST/ALT ratio predicts cirrhosis in patients with chronic hepatitis C virus infection. Am J Gastroenterol 1998; 93:44-48. doi: 10.1111/j.1572-0241.1998.044_c.x.

[49] Angulo P, Keach JC, Batts KP, Lindor KD. Independent predictors of liver fibrosis in patients with nonalcoholic steatohepatitis. Hepatology 1999; 30:1356-1362. doi: 10.1002/hep.510300604.

[50] McPherson S, Anstee QM, Henderson E, Day CP, Burt AD. Are simple noninvasive scoring systems for fibrosis reliable in patients with NAFLD and normal ALT levels? Eur J Gastroenterol Hepatol 2013;25:652-658. doi: 10.1097/MEG.0b013e32835d72cf.

[51] Goh GB, Pagadala MR, Dasarathy J, Unalp-Arida A, Pai RK, Yerian L, et al. Age impacts ability of aspartate-alanine aminotransferase ratio to predict advanced fibrosis in nonalcoholic Fatty liver disease. Dig Dis Sci 2015;60: 1825-1831. doi: 10.1007/s10620-015-3529-8.

[52] Vallet-Pichard A, Mallet V, Nalpas B, Verkarre V, Nalpas A, Dhalluin-Venier $V$, et al. FIB-4: an inexpensive and accurate marker of fibrosis in HCV infection. comparison with liver biopsy and fibrotest. Hepatology 2007;46:32-36. doi: 10.1002/hep.21669.

[53] Sun W, Cui H, Li N, Wei Y, Lai S, Yang Y, et al. Comparison of FIB-4 index, NAFLD fibrosis score and BARD score for prediction of advanced fibrosis in adult patients with non-alcoholic fatty liver disease: A meta-analysis study. Hepatol Res 2016;46:862-870. doi: 10.1111/hepr.12647.

[54] Sumida $Y$, Yoneda $M$, Hyogo $H$, Itoh $Y$, Ono $M$, Fujii $H$, et al. Validation of the FIB4 index in a Japanese nonalcoholic fatty liver disease population. BMC Gastroenterol 2012;12:2. doi: 10.1186/1471-230X-12-2.

[55] Siddiqui MS, Patidar KR, Boyett S, Luketic VA, Puri P, Sanyal AJ. Performance of non-invasive models of fibrosis in predicting mild to moderate fibrosis in patients with non-alcoholic fatty liver disease. Liver Int 2016;36: 572-579. doi: 10.1111/liv.13054.

[56] Ratziu V, Giral P, Charlotte F, Bruckert E, Thibault V, Theodorou I, et al. Live fibrosis in overweight patients. Gastroenterology 2000;118:1117-1123. doi: 10.1016/S0016-5085(00)70364-7.

[57] Harrison SA, Oliver D, Arnold HL, Gogia S, Neuschwander-Tetri BA. Development and validation of a simple NAFLD clinical scoring system for identifying patients without advanced disease. Gut 2008;57:1441-1447. doi: 10 . 1136/gut.2007.146019.

[58] Cichoż-Lach H, Celiński K, Prozorow-Król B, Swatek J, Słomka M, Lach T. The BARD score and the NAFLD fibrosis score in the assessment of advanced liver fibrosis in nonalcoholic fatty liver disease. Med Sci Monit 2012;18:CR735-CR740. doi: 10.12659/MSM.883601.

[59] Ruffillo G, Fassio E, Alvarez E, Landeira G, Longo C, Domínguez N, et al. Comparison of NAFLD fibrosis score and BARD score in predicting fibrosis in nonalcoholic fatty liver disease. J Hepatol 2011;54:160-163. doi: 10. 1016/j.jhep.2010.06.028.

[60] Raszeja-Wyszomirska J, Szymanik B, Ławniczak M, Kajor M, Chwist A, Milkiewicz $\mathrm{P}$, et al. Validation of the BARD scoring system in Polish patients with nonalcoholic fatty liver disease (NAFLD). BMC Gastroenterol 2010;10:67. doi: 10.1186/1471-230X-10-67.

[61] Kaswala $\mathrm{DH}$, Lai $\mathrm{M}$, Afdhal $\mathrm{NH}$. Fibrosis assessment in nonalcoholic fatty liver disease (NAFLD) in 2016. Dig Dis Sci 2016;61:1356-1364. doi: 10 . 1007/s10620-016-4079-4.

[62] Guha IN, Parkes J, Roderick P, Chattopadhyay D, Cross R, Harris S, et al. Noninvasive markers of fibrosis in nonalcoholic fatty liver disease: Validating the European Liver Fibrosis Panel and exploring simple markers. Hepatology 2008;47:455-460. doi: 10.1002/hep.21984.

[63] Lichtinghagen R, Pietsch D, Bantel H, Manns MP, Brand K, Bahr MJ. The Enhanced Liver Fibrosis (ELF) score: normal values, influence factors and proposed cut-off values. J Hepatol 2013;59:236-242. doi: 10.1016/j.jhep. 2013.03.016.

[64] Nobili V, Parkes J, Bottazzo G, Marcellini M, Cross R, Newman D, et al. Performance of ELF serum markers in predicting fibrosis stage in pediatric non-alcoholic fatty liver disease. Gastroenterology 2009;136:160-167. doi: 10.1053/j.gastro.2008.09.013.

[65] Parkes J, Roderick P, Harris S, Day C, Mutimer D, Collier J, et al. Enhanced liver fibrosis test can predict clinical outcomes in patients with chronic liver disease. Gut 2010;59:1245-1251. doi: 10.1136/gut.2009.203166.

[66] Glen J, Floros L, Day C, Pryke R. Guideline Development Group. Nonalcoholic fatty liver disease (NAFLD): summary of NICE guidance. BMJ 2016;354:i4428. doi: 10.1136/bmj.i4428.

[67] Calès $P$, Oberti F, Michalak $S$, Hubert-Fouchard I, Rousselet MC, Konaté $A$ et al. A novel panel of blood markers to assess the degree of liver fibrosis. Hepatology 2005;42:1373-1381. doi: 10.1002/hep.20935.
[68] Calès $P$, Lainé $F$, Boursier J, Deugnier $Y$, Moal V, Oberti $F$, et al. Comparison of blood tests for liver fibrosis specific or not to NAFLD. J Hepatol 2009;50: 165-173. doi: 10.1016/j.jhep.2008.07.035.

[69] Sandrin L, Fourquet B, Hasquenoph JM, Yon S, Fournier C, Mal F, et al. Transient elastography: a new noninvasive method for assessment of hepatic fibrosis. Ultrasound Med Biol 2003;29:1705-1713. doi: 10.1016/ j.ultrasmedbio.2003.07.001.

[70] Foucher J, Chanteloup E, Vergniol J, Castéra L, Le Bail B, Adhoute X, et al. Diagnosis of cirrhosis by transient elastography (FibroScan): a prospective study. Gut 2006;55:403-408. doi: 10.1136/gut.2005.069153.

[71] Castéra L, Vergniol J, Foucher J, Le Bail B, Chanteloup E, Haaser M, et al. Prospective comparison of transient elastography, Fibrotest, APRI, and liver biopsy for the assessment of fibrosis in chronic hepatitis C. Gastroenterology 2005;128:343-350. doi: 10.1053/j.gastro.2004.11.018.

[72] Chang PE, Goh GB, Ngu JH, Tan HK, Tan CK. Clinical applications, limitations and future role of transient elastography in the management of liver disease. World J Gastrointest Pharmacol Ther 2016;7:91-106. doi: 10. 4292/wjgpt.v7.i1.91.

[73] Yoneda M, Yoneda M, Mawatari $\mathrm{H}$, Fujita $\mathrm{K}$, Endo $\mathrm{H}$, Iida $\mathrm{H}$, et al. Noninvasive assessment of liver fibrosis by measurement of stiffness in patients with nonalcoholic fatty liver disease (NAFLD). Dig Liver Dis 2008;40:371-378. doi: 10.1016/j.dld.2007.10.019.

[74] Yoneda M, Yoneda M, Fujita K, Inamori M, Tamano M, Hiriishi $\mathrm{H}$, et al. Transient elastography in patients with non-alcoholic fatty liver disease (NAFLD). Gut 2007;56:1330-1331. doi: 10.1136/gut.2007.126417.

[75] Wong VW, Vergniol J, Wong GL, Foucher J, Chan HL, Le Bail B, et al. Diagnosis of fibrosis and cirrhosis using liver stiffness measurement in nonalcoholic fatty liver disease. Hepatology 2010;51:454-462. doi: 10.1002/hep. 23312.

[76] Kwok R, Tse YK, Wong GL, Ha Y, Lee AU, Ngu MC, et al. Systematic review with meta-analysis: non-invasive assessment of non-alcoholic fatty liver disease-the role of transient elastography and plasma cytokeratin-18 fragments. Aliment Pharmacol Ther 2014;39:254-269. doi: 10.1111/apt. 12569.

[77] Coco B, Oliveri F, Maina AM, Ciccorossi P, Sacco R, Colombatto $P$, et al. Transient elastography: a new surrogate marker of liver fibrosis influenced by major changes of transaminases. J Viral Hepat 2007;14:360-369. doi: 10.1111/j.1365-2893.2006.00811.x.

[78] Wong GL, Wong VW, Choi PC, Chan AW, Chum RH, Chan HK, et al. Assessment of fibrosis by transient elastography compared with liver biopsy and morphometry in chronic liver diseases. Clin Gastroenterol Hepatol 2008;6: 1027-1035. doi: 10.1016/j.cgh.2008.02.038.

[79] Arena U, Vizzutti F, Corti G, Ambu S, Stasi C, Bresci S, et al. Acute viral hepatitis increases liver stiffness values measured by transient elastography. Hepatology 2008;47:380-384. doi: 10.1002/hep.22007.

[80] Sagir A, Erhardt A, Schmitt M, Häussinger D. Transient elastography is unreliable for detection of cirrhosis in patients with acute liver damage. Hepatology 2008;47:592-595. doi: 10.1002/hep.22056.

[81] Petta S, Wong VW, Cammà C, Hiriart JB, Wong GL, Marra F, et al. Improved noninvasive prediction of liver fibrosis by liver stiffness measurement in patients with nonalcoholic fatty liver disease accounting for controlled attenuation parameter values. Hepatology 2017;65:1145-1155. doi: 10 . 1002/hep. 28843

[82] Millonig G, Reimann FM, Friedrich S, Fonouni H, Mehrabi A, Büchler MW et al. Extrahepatic cholestasis increases liver stiffness (FibroScan) irrespective of fibrosis. Hepatology 2008;48:1718-1723. doi: 10.1002/hep.22577.

[83] Millonig G, Friedrich S, Adolf S, Fonouni H, Golriz M, Mehrabi A, et al. Liver stiffness is directly influenced by central venous pressure. J Hepatol 2010 52:206-210. doi: 10.1016/j.jhep.2009.11.018.

[84] Mederacke I, Wursthorn K, Kirschner J, Rifai K, Manns MP, Wedemeyer H, et al. Food intake increases liver stiffness in patients with chronic or resolved hepatitis C virus infection. Liver Int 2009;29:1500-1506. doi: 10.1111/j.1478-3231.2009.02100.x.

[85] Castéra L, Foucher J, Bernard PH, Carvalho F, Allaix D, Merrouche W, et al Pitfalls of liver stiffness measurement: a 5-year prospective study of 13,369 examinations. Hepatology 2010;51:828-835. doi: 10.1002/hep.23425.

[86] Wong GL, Wong VW, Chim AM, Yiu KK, Chu SH, Li MK, et al. Factors associated with unreliable liver stiffness measurement and its failure with transient elastography in the Chinese population. J Gastroenterol Hepatol 2011; 26:300-305. doi: 10.1111/j.1440-1746.2010.06510.x.

[87] de Lédinghen V, Vergniol J, Foucher J, El-Hajbi F, Merrouche W, Rigalleau V. Feasibility of liver transient elastography with FibroScan using a new probe for obese patients. Liver Int 2010;30:1043-1048. doi: 10.1111/j.14783231.2010.02258.x

[88] de Lédinghen V, Wong VW, Vergniol J, Wong GL, Foucher J, Chu SH, et al. Diagnosis of liver fibrosis and cirrhosis using liver stiffness measurement: comparison between $M$ and XL probe of FibroScan ${ }^{\circledR}$. J Hepatol 2012:56: 833-839. doi: 10.1016/j.jhep.2011.10.017.

[89] Wong VW, Vergniol J, Wong GL, Foucher J, Chan AW, Chermak F, et al. Liver stiffness measurement using $\mathrm{XL}$ probe in patients with nonalcoholic fatty 
liver disease. Am J Gastroenterol 2012;107:1862-1871. doi: 10.1038/ajg. 2012.331.

[90] Chen J, Talwalkar JA, Yin M, Glaser KJ, Sanderson SO, Ehman RL. Early detection of nonalcoholic steatohepatitis in patients with nonalcoholic fatty liver disease by using MR elastography. Radiology 2011;259:749756. doi: 10.1148/radiol.11101942.

[91] Venkatesh SK, Wang G, Teo LL, Ang BW. Magnetic resonance elastography of liver in healthy Asians: normal liver stiffness quantification and reproducibility assessment. J Magn Reson Imaging 2014;39:1-8. doi: 10. 1002/jmri.24084.

[92] Yin M, Talwalkar JA, Glaser KJ, Manduca A, Grimm RC, Rossman PJ, et al. Assessment of hepatic fibrosis with magnetic resonance elastography. Clin Gastroenterol Hepatol 2007;5:1207-1213.e2. doi: 10.1016/j.cgh.2007. 06.012.

[93] Kim D, Kim WR, Talwalkar JA, Kim HJ, Ehman RL. Advanced fibrosis in nonalcoholic fatty liver disease: noninvasive assessment with MR elastography. Radiology 2013;268:411-419. doi: 10.1148/radiol.13121193.

[94] Singh S, Venkatesh SK, Loomba R, Wang Z, Sirlin C, Chen J, et al. Magnetic resonance elastography for staging liver fibrosis in non-alcoholic fatty liver disease: a diagnostic accuracy systematic review and individual participant data pooled analysis. Eur Radiol 2016;26:1431-1440. doi: 10.1007/ s00330-015-3949-z.

[95] Imajo K, Kessoku T, Honda $Y$, Tomeno W, Ogawa $Y$, Mawatari $\mathrm{H}$, et al. Magnetic resonance imaging more accurately classifies steatosis and fibrosis in patients with nonalcoholic fatty liver disease than transient elastography. Gastroenterology 2016;150:626-637.e7. doi: 10.1053/j.gastro.2015.11. 048.

[96] Park CC, Nguyen P, Hernandez C, Bettencourt R, Ramirez K, Fortney L, et al. Magnetic resonance elastography vs transient elastography in detection of fibrosis and noninvasive measurement of steatosis in patients with biopsyproven nonalcoholic fatty liver disease. Gastroenterology 2017;152:598607.e2. doi: $10.1053 / j$.gastro.2016.10.026.

[97] Cui J, Heba E, Hernandez C, Haufe W, Hooker J, Andre MP, et al. Magnetic resonance elastography is superior to acoustic radiation force impulse for the Diagnosis of fibrosis in patients with biopsy-proven nonalcoholic fatty liver disease: A prospective study. Hepatology 2016;63:453-461. doi: 10. 1002/hep.28337.

[98] Loomba R, Cui J, Wolfson T, Haufe W, Hooker J, Szeverenyi N, et al. Novel 3D Magnetic Resonance Elastography for the Noninvasive Diagnosis of Advanced Fibrosis in NAFLD: A Prospective Study. Am J Gastroenterol 2016;111:986-994. doi: 10.1038/ajg.2016.65.

[99] Yoon KT, Lim SM, Park JY, Kim DY, Ahn SH, Han KH, et al. Liver stiffness measurement using acoustic radiation force impulse (ARFI) elastography and effect of necroinflammation. Dig Dis Sci 2012;57:1682-1691. doi: $10.1007 / \mathrm{s} 10620-012-2044-4$.
[100] Liu H, Fu J, Hong R, Liu L, Li F. Acoustic radiation force impulse elastography for the non-invasive evaluation of hepatic fibrosis in non-alcoholic fatty liver disease patients: a systematic review \& meta-analysis. PLoS One 2015;10: e0127782. doi: 10.1371/journal.pone.0127782.

[101] Cassinotto C, Boursier J, de Lédinghen V, Lebigot J, Lapuyade B, Cales P, et al. Liver stiffness in nonalcoholic fatty liver disease: A comparison of supersonic shear imaging, FibroScan, and ARFI with liver biopsy. Hepatology 2016;63:1817-1827. doi: 10.1002/hep.28394.

[102] Bota S, Herkner H, Sporea I, Salzl P, Sirli R, Neghina AM, et al. Metaanalysis: ARFI elastography versus transient elastography for the evaluation of liver fibrosis. Liver Int 2013;33:1138-1147. doi: 10.1111/liv.12240.

[103] Jayakumar S, Harrison SA, Loomba R. Noninvasive markers of fibrosis and inflammation in nonalcoholic fatty liver disease. Curr Hepatol Rep 2016;15: 86-95. doi: 10.1007/s11901-016-0296-8.

[104] Ferraioli G, Tinelli C, Zicchetti M, Above E, Poma G, Di Gregorio M, et al. Reproducibility of real-time shear wave elastography in the evaluation of liver elasticity. Eur J Radiol 2012;81:3102-3106. doi: 10.1016/j.ejrad. 2012.05.030.

[105] Bercoff J, Tanter M, Fink M. Supersonic shear imaging: a new technique for soft tissue elasticity mapping. IEEE Trans Ultrason Ferroelectr Freq Control 2004;51:396-409. doi: 10.1109/TUFFC.2004.1295425.

[106] Muller M, Gennisson JL, Deffieux T, Tanter M, Fink M. Quantitative viscoelasticity mapping of human liver using supersonic shear imaging: preliminary in vivo feasibility study. Ultrasound Med Biol 2009;35:219-229. doi: 10.1016/j.ultrasmedbio.2008.08.018.

[107] Bavu E, Gennisson JL, Couade M, Bercoff J, Mallet V, Fink M, et al. Noninvasive in vivo liver fibrosis evaluation using supersonic shear imaging: a clinical study on 113 hepatitis C virus patients. Ultrasound Med Biol 2011; 37:1361-1373. doi: 10.1016/j.ultrasmedbio.2011.05.016.

[108] Cassinotto C, Lapuyade B, Mouries A, Hiriart JB, Vergniol J, Gaye D, et al. Non-invasive assessment of liver fibrosis with impulse elastography: comparison of Supersonic Shear Imaging with ARFI and FibroScan ${ }^{\circledR}$. J Hepatol 2014;61:550-557. doi: 10.1016/j.jhep.2014.04.044.

[109] Alkhouri N, Feldstein AE. Noninvasive diagnosis of nonalcoholic fatty liver disease: Are we there yet? Metabolism 2016;65:1087-1095. doi: 10. 1016/j.metabol.2016.01.013.

[110] Petta S, Vanni E, Bugianesi E, Di Marco V, Cammà C, Cabibi D, et al. The combination of liver stiffness measurement and NAFLD fibrosis score improves the noninvasive diagnostic accuracy for severe liver fibrosis in patients with nonalcoholic fatty liver disease. Liver Int 2015;35: 1566-1573. doi: 10.1111/liv.12584.

[111] Tapper EB, Sengupta N, Hunink MG, Afdhal NH, Lai M. Cost-effective evaluation of nonalcoholic fatty liver disease with nafld fibrosis score and vibration controlled transient elastography. Am J Gastroenterol 2015;110: 1298-1304. doi: 10.1038/ajg.2015.241. 